\title{
Effects of Air Pollution on Public and Private Health Expenditures in Iran: A Time Series Study (1972-2014)
}

\author{
Pouran Raeissi', Touraj Harati-Khalilabad ${ }^{2}$, Aziz Rezapour ${ }^{2,3}$, Seyed Yaser Hashemi ${ }^{4}$, Abdoreza Mousavi' ${ }^{2}$, \\ Saeed Khodabakhshzadeh ${ }^{5}$
}

${ }^{1}$ Department of Health Services Management, School of Health Management and Information Sciences, Iran University of Medical Sciences, Tehran, Iran; ${ }^{2}$ Department of Health Economics, School of Health Management and Information Science, Iran University of Medical Sciences, Tehran, Iran; ${ }^{3}$ Health Management and Economics Research Center, Iran University of Medical Sciences, Tehran, Iran; ${ }^{4}$ Department of Environmental Health Engineering, School of Public Health, Tehran University of Medical Sciences, Tehran, Iran; ${ }^{5}$ Bam University of Medical Sciences, Bam, Iran

Objectives: Environmental pollution is a negative consequence of the development process, and many countries are grappling with this phenomenon. As a developing country, Iran is not exempt from this rule, and Iran pays huge expenditures for the consequences of pollution. The aim of this study was to analyze the long- and short-run impact of air pollution, along with other health indicators, on private and public health expenditures.

Methods: This study was an applied and developmental study. Autoregressive distributed lag estimating models were used for the period of 1972 to 2014. In order to determine the co-integration between health expenditures and the infant mortality rate, fertility rate, per capita income, and pollution, we used the Wald test in Microfit version 4.1. We then used Eviews version 8 to evaluate the stationarity of the variables and to estimate the long- and short-run relationships.

Results: Long-run air pollution had a positive and significant effect on health expenditures, so that a $1.00 \%$ increase in the index of carbon dioxide led to an increase of $3.32 \%$ and $1.16 \%$ in public and private health expenditures, respectively. Air pollution also had a greater impact on health expenditures in the long term than in the short term.

Conclusions: The findings of this study indicate that among the factors affecting health expenditures, environmental quality and contaminants played the most important role. Therefore, in order to reduce the financial burden of health expenditures in Iran, it is essential to reduce air pollution by enacting and implementing laws that protect the environment.

Key words: Air pollution, Infant mortality, Fertility, Income, Health expenditures, Iran

Received: September 24, 2017 Accepted: May 14, 2018

Corresponding author: Touraj Harati-Khalilabad, PhD Department of Health Economics, School of Health Management and Information Sciences, Iran University of Medical Sciences, Valiasr Street, Tehran 1449614535, Iran

E-mail: toorajharati@gmail.com

This is an Open Access article distributed under the terms of the Creative Commons Attribution Non-Commercial License (http://creativecommons.org/licenses/by$\mathrm{nc} / 4.0 /$ ) which permits unrestricted non-commercial use, distribution, and reproduction in any medium, provided the original work is properly cited.

\section{INTRODUCTION}

Health expenditures are an integral part of individuals' lives, making them an essential issue for society as a whole [1]. Health is of such paramount importance that many families are willing to pay exorbitant costs for healthcare services [2]. In this regard, as the process of development has proceeded in various countries, with concomitant increases in environmental pollution, families' demands for healthcare services 
have increased, leading to increases in health expenditures. In fact, in most developing countries, increases in environmental pollution and health expenditures have outpaced economic growth [1].

The increasing trend in health expenditures and their determinants in developing countries, particularly Iran, pose a major challenge for the economy in the health sector. Factors affecting health expenditures and their determinants have been of great interest to economists since the 1970s [3], and many studies have focused on identifying and investigating factors affecting health expenditures. The quality of the environment is a factor that has generally been neglected in many studies [4]; however, the environment and environmental pollution are among the most important determinants of expenditures in the health sector [5-8].

Similarly, air pollution has both chronic and acute effects on human health and contribute to increase morbidity and hospital admissions [9]. Its impact is so astonishing that this phenomenon has increasingly been the focus of attention of various studies such as those of Boachie et al. [1], Fattahi et al. [3,4], Jie [8], and Mohammadzadeh et al. [10]. In these studies, the researchers concluded that air pollution had a significant and positive impact on health expenditures. Hence, air pollution is one of the most fundamental management challenges in developed and developing countries all around the world. With the increasing development of communities, air pollution has become a serious threat to individuals' health. According to the World Health Organization, approximately 3 million people annually die of air pollution [11]. According to previous studies, the mortality rate increases by $1-3 \%$ with each increase of $10 \mu \mathrm{g} / \mathrm{m}^{3}$ in the particulate matter in the air [3].

In addition to an increased mortality rate, pollution is accompanied by extortionate health and economic consequences. Some health consequences include an increased burden of cardiovascular diseases and decrease in visibility. Other consequences of air pollution include damage to plants, acid rain, and global warming. According to some studies, the annual economic costs of mortality in premature infants and annual health and mortality costs imposed by air pollution were 1.431 and 1.575 billion dollars in European countries and America, respectively.
It has been predicted that health expenditures caused by air pollution will increase from 21 billion dollars in 2015 to 176 billion dollars in 2060. Meanwhile, China and Sweden-with 1032833 and 40 deaths in 2012, respectively—were globally ranked first and last in terms of the health burden of air pollution and poor environmental quality. Iran was ranked 16th in terms of pollution-induced mortality [12]. Table 1 presents the frequency of air pollution-attributed deaths in Iran and some other countries in 2012 [13].

According to statistics provided by the World Bank on the impacts of air pollution in Iran, the annual loss due to air pollution was roughly 7, 8, and 10 billion dollars in 2004, 2006, and 2010, respectively. The World Bank estimated that the annual economic impact of air pollution in Iran reached 16 billion dollars in 2016 [14].

Generally, air pollution has a significant impact on health expenditures and costs imposed by diseases; according to a World Bank report, diseases caused by urban air pollution annually cost 260 million dollars (equivalent to 2100 billion rials) in Iran, and damage Iran's economy by as much as $0.023 \%$ of its gross domestic product (GDP). Another World Bank study [15] showed that the annual death and prevalence of illness caused by urban air pollution cost about 5100 billion rials and 4100 billion rials in Iran, respectively. Furthermore, the costs associated with diseases in Iran have been estimated to be approximately 2100 billion rials. According to research conducted in 2013 , air pollution leads to $14 \%$ of deaths from stroke in Iran [16]. These statistics reveal the negative consequences and economic burden of disease induced by air pollution in Iran [17].

Therefore, given the increasing trend in health expenditures and the resultant financial challenges for most countries, there is an urgent need for more attention to be paid to the factors affecting health expenses [18]. With increasing air pollution in metropolitan cities and the associated burden imposed by air pollution, a gap continues to be present in the relevant literature in terms of examining the role of these factors in growing health expenditures, requiring further research. Thus, the current study aimed to investigate these factors, focusing on the effect of environmental pollution on public health expenditures (PuHE) and private health expenditures (PrHE) in Iran.

Table 1. Frequency of air pollution-attributed deaths in Iran and some other countries in 2012 [13]

\begin{tabular}{lcccccccc}
\hline Country & China & India & Indonesia & USA & Iran & Canada & Norway & Sweden \\
\hline No. of death & 1032833 & 621137 & 61792 & 38042 & 26267 & 1886 & 636 & 40 \\
\hline
\end{tabular}


This study is novel in that it distinguished PuHE versus PrHE and focused on health aspects, such as the infant mortality rate, along with environmental pollution. Another novel aspect of this study relates to the time series methodology adopted in this study, as well as the use of data obtained from recent years (1972-2014).

\section{METHODS}

This study was conducted in Iran using a time series methodology, and the data were collected during 1972-2014. Microfit version 4.1 (Oxford University Press, London, UK) and Eviews version 8 (IHS Global Inc., Irvine, CA, USA) were used. The basic model employed was adopted from Karatzas' study [19]. The model was extended based on several other studies in which socioeconomic factors were explored as the main determinants of health expenditures [20]. Finally, the multivariate models used in the current study consisted of environmental aspects with a relatively clear relevance to the health sector, enabling them to be considered as the main determinants of health expenditures. In this model, all variables were included in the form of natural logarithms in order to calculate the elasticity.

$\ln P u H E_{\mathrm{t}}=\beta_{0}+\beta_{1} \ln G D P_{t}+\beta_{2} \ln C O_{2 t}+\beta_{3} \ln I M R_{t}+\beta_{4} \ln F R_{t}+D U M+\varepsilon_{t} \quad(1)$

$\ln P r H E_{\mathrm{t}}=\beta_{0}+\beta_{1} \ln G D P_{t}+\beta_{2} \ln C O_{2 t}+\beta_{3} \ln I M R_{t}+\beta_{4} \ln F R_{t}+D U M+\varepsilon_{t}$

Where $\ln P u H E_{t}$ and $\ln \mathrm{PrHE}_{t}$ are PuHE and PrHE per capita at constant prices in 2004, respectively; additionally, $\ln G D P_{t}$ represents the GDP per capita at constant prices in 2004, $\ln \mathrm{CO}_{2 t}$ denotes pollution caused by carbon dioxide in metric

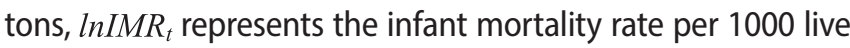
births, and $\ln F R_{t}$ is the fertility rate. Additionally, a dummy variable (DUM) was used to consider the structural deficit of GDP in Iran as DUM =0 for years prior to 1992 and $D U M=1$ for the following years.

In order to estimate and analyze long-term relationships and dynamic interactions between the variables under study, the autoregressive distributed lag (ARDL) method introduced by Pesaran et al. [21] in 2001 was used. This method is superior to other co-integration methods because short-term dynamics are not included in the error correction section and because this method can be used regardless of the type of variables (I[1], I[0] or a combination of both types). Based on econometric theories, if variables are co-integrated, there is then at least a linear relationship between the variables in the model. Prior to using the ordinary least squares (OLS) method, the stationarity test should be carried out to estimate the relationships.

The extended Dickey-Fuller test was then used for the firstorder divergence of variables to determine the degree of cointegration among the model variables. In the first stage, each equation was estimated based on the OLS method. In the second stage, the Wald test was used to explore the long-term relationships among the variables. According the hypothesis of Pesaran et al. [21] and considering $\lambda_{x y}=0$ and $0 \neq \mu$, the relationship between the dependent and independent variables in equations 3 and 4 was as follows:

$\ln P u H E_{t}=\beta_{0}+\beta_{1} \operatorname{lnGDP} P_{t-1}+\beta_{2} \operatorname{lnCO2} 2_{t-1}+\beta_{3} \operatorname{lnIMR_{t-1}}+\beta_{4} \ln F R_{t-1}+$ $\beta_{5, i} \sum_{i=1}^{p} \Delta \operatorname{lnGDP} P_{t-1}+\beta_{6, i} \sum_{i=1}^{q_{1}} \Delta \ln C 02_{t-1}+\beta_{7, i} \sum_{i=1}^{q_{2}} \Delta \ln I M R_{t-1}+$ $\beta_{8, i} \sum_{i=1}^{q_{3}} \Delta \ln F R_{t-1}+\varepsilon_{t}$

$\ln P r H E_{t}=\beta_{0}+\beta_{1} \operatorname{lnGDP} P_{t-1}+\beta_{2} \operatorname{lnCO2} 2_{t-1}+\beta_{3} \operatorname{lnIMR_{t-1}}+\beta_{4} \operatorname{lnFR} R_{t-1}+$ $\beta_{5, i} \sum_{i=1}^{p} \Delta \ln G D P_{t-1}+\beta_{6, i} \sum_{i=1}^{q_{1}} \Delta \ln C 02_{t-1}+\beta_{7, i} \sum_{i=1}^{q_{2}} \Delta \ln I M R_{t-1}+$ $\beta_{8, i} \sum_{i=1}^{q_{3}} \Delta \ln F R_{t-1}+\varepsilon_{t}$

Where $\Delta$ represents first-order divergence. As an ARDL model, this model used the Schwartz Bayesian criterion (SBC) to determine the length of lags. The OLS method was then employed to estimate equations 3 and 4. Further, the F-test (Wald test) was used to verify the presence or absence of longterm relationships. The null hypothesis $\left(H_{0}\right)$ indicated that there was no long-term relationship, while the other hypothesis $\left(H_{1}\right)$ assumed the existence of a long-term relationship between the variables. The test hypotheses were as follows:

$$
\left\{\begin{array}{l}
H_{0}: \beta_{1}=0 \text { and } \beta_{2}=\beta_{3}=\beta_{4}=\beta_{5}=\beta_{6}=0 \\
H_{1}: \beta_{1} \neq 0 \text { and } \beta_{2} \neq \beta_{3} \neq \beta_{4} \neq \beta_{5} \neq \beta_{6} \neq 0
\end{array}\right.
$$

In this way, 2 critical bounds were provided: the upper bound for series I(1) and the lower bound for series I( 0 ). In this method, if the calculated F-value is greater than the upper bound, the $\mathrm{Ho}$ is rejected, while if the F-value is smaller than the lower bound, the Ho is not rejected. If the F-value is within the bounds, no conclusion can be made unless the degree of integration is specified for the variables [21]. Finally, the error correction model was defined within the framework of the ARDL model. 


$$
\begin{aligned}
& \ln \operatorname{PrHE}_{t}=\mu+\sum_{i=1}^{p} \emptyset_{i} \Delta \operatorname{lnPrHE} E_{t-1}+\sum_{j=1}^{q_{1}} \varphi_{j} \Delta \operatorname{lnGDP_{t-1}}+\sum_{m=1}^{q_{2}} \gamma_{m} \Delta \operatorname{lnCO2_{t-1}} \\
& +\sum_{r=1}^{q_{3}} \delta_{r} \Delta \operatorname{lnIMR_{t-1}}+\sum_{s=1}^{q_{4}} \rho_{s} \Delta \ln F R_{t-1}+\omega_{e c m_{\mathrm{t}-1}}+\varepsilon_{\mathrm{t}} \\
& \ln P u H E_{t}=\mu+\sum_{i=1}^{p} \emptyset_{i} \Delta \operatorname{lnPrH} E_{t-1}+\sum_{j=1}^{q_{1}} \varphi_{j} \Delta \ln G D P_{t-1}+\sum_{m=1}^{q_{2}} \gamma_{m} \Delta \operatorname{lnCO} 2_{t-1} \\
& +\sum_{r=1}^{q_{3}} \delta_{r} \ln \Delta I M R_{t-1}+\sum_{s=1}^{q_{4}} \rho_{s} \Delta \ln F R_{t-1}+\omega_{e c m_{\mathrm{t}-1}}+\varepsilon_{\mathrm{t}}
\end{aligned}
$$

In the above equations, $\Delta$ is first-order divergence and $(\delta, \rho$, $\gamma, \varphi, \varnothing)$ and $\omega$ are short-term dynamic and adjustment speed coefficients, respectively.

\section{RESULTS}

To explore the impact of environmental quality on health expenditures, $\mathrm{CO}_{2}$ emissions were used as an indicator of environmental quality, as well as other independent variables such as per capita income, infant mortality rate, and fertility rate. In 2 separate models, the impacts of independent variables on PrHE and PuHE were examined in terms of constant prices in 2004. All variables were included in the model as natural logarithm-transformed values.

Table 2 presents descriptive statistics of the selected variables over the period 1972-2014. The summary of common statistics contains the mean, median, standard deviation, maximum, and minimum of each series after log-transformation.

The Dickey-Fuller test was first used to determine the stationarity of the variables. Based on this test, some variables were stationary at level and some other variables were stationary at first-order divergence.

The SBC was run to determine the optimal lag, and thirdrank and first rank lags were selected as optimal for models 1 and 2, respectively. The Wald test was used to determine the long-term relationships between health expenditures and oth- er independent variables. The test statistics in this study for the first and second models were found to be $F(5,27)=8.779, p<$ 0.001 and $F(5,27)=8.887, p<0.001$, respectively, indicating that the Ho suggesting no co-integration between the model variables was rejected. Hence, the results indicate a long-term relationship between PuHE and PrHE and the variables included in the model. The results of the ARDL analysis confirming the presence of a long-term relationship are reported in Table 3.

In the results presented in the tables, the coefficients represent the percentage of variation in dependent variables per $1 \%$ long-term variation of the independent variables. It should be noted that there was no endogeneity problem in the models.

Regarding the results of the estimations of long-term relationships in the 2 models, it was inferred that the coefficient of $\mathrm{CO}_{2}$ emissions was positive and meaningful at a significance level of 0.05 , so that a $1.00 \%$ increase in this variable resulted in 3.22 and $1.16 \%$ increases in PuHE and PrHE, respectively. Furthermore, a $1.00 \%$ increase in per capita income increased PuHE and PrHE by as much as 0.51 and $0.43 \%$; however, these values were not significant at 0.05 . In the long-run models, a $1.00 \%$ increase in the infant mortality rate caused 1.47 and $0.09 \%$ increases in PuHE and PrHE, respectively. The fertility

Table 3. The results of long-term coefcients for the ARDL method $(0,2,2,1,0,1)$ and $(1,0,0,0,0,2)$ based on the SBC

\begin{tabular}{lccccc}
\hline $\begin{array}{l}\text { Dependent } \\
\text { variable }\end{array}$ & \multicolumn{2}{c}{ InPuHE } & & \multicolumn{2}{c}{ InPrHE } \\
\cline { 2 - 3 } \cline { 5 - 6 } & Coefficient & $\boldsymbol{t}$-value (prob) & & Coefficient & $\boldsymbol{t}$-value (prob) \\
\hline InCO 2 & 3.22 & $3.46(<0.001)$ & & 1.16 & $2.71(0.01)$ \\
InGDP & 0.51 & $1.30(0.20)$ & & 0.43 & $1.30(0.09)$ \\
InFR & 0.68 & $1.30(0.20)$ & & 0.36 & $1.30(0.30)$ \\
InIMR & 1.47 & $3.48(<0.001)$ & & 0.09 & $3.48(0.003)$ \\
DUM & 1.41 & $3.20(0.003)$ & & 1.23 & $3.40(<0.001)$ \\
C & -9.50 & $-1.18(0.22)$ & & 2.89 & $0.53(0.53)$ \\
\hline
\end{tabular}

ARDL, autoregressive distributed lag; SBC, Schwartz Bayesian criterion; InPuHE, logarithm public health expenditures; InPrHE, logarithm private health expenditures; InCO $\mathrm{C}_{2}$ logarithm of carbon dioxide; InGDP, logarithm of gross domestic product; InFR, logarithm of fertility rate; InIMR, logarithm of infant mortality rate; DUM, dummy variable; $C$, constant term.

Table 2. Descriptive statistics of the selected variables

\begin{tabular}{lcccccc}
\hline Variables & $\begin{array}{c}\text { Public health } \\
\text { expenditures }\end{array}$ & $\begin{array}{c}\text { Private health } \\
\text { expenditures }\end{array}$ & Carbon dioxide & Fertility rate & $\begin{array}{c}\text { Infant mortality } \\
\text { rate }\end{array}$ & $\begin{array}{c}\text { Gross domestic } \\
\text { product }\end{array}$ \\
\hline Mean \pm SD & $11.39 \pm 1.06$ & $12.01 \pm 1.11$ & $1.50 \pm 0.90$ & $1.03 \pm 0.49$ & $3.32 \pm 0.50$ & $16.30 \pm 0.49$ \\
Maximum & 12.39 & 13.66 & 2.13 & 1.87 & 4.83 & 17.20 \\
Minimum & 10.05 & 11.61 & 1.01 & 0.53 & 2.63 & 16.24 \\
Total (n) & 40 & 40 & 40 & 40 & 40 & 40 \\
\hline
\end{tabular}

SD, standard deviation. 
Table 4. The results of the ECM for the ARDL method $(0,2,2,1$, $0,1)$ and $(1,0,0,0,0,2)$ based on the SBC

\begin{tabular}{lcccccc}
\hline \multirow{2}{*}{$\begin{array}{c}\text { Dependent } \\
\text { variable }\end{array}$} & \multicolumn{2}{c}{ InPuHE } & & \multicolumn{2}{c}{ InPrHE } \\
\cline { 2 - 3 } \cline { 5 - 6 } & Coefficient & t-value (prob) & & Coefficient & t-value (prob) \\
\hline dlnCO $_{2}$ & 1.78 & $2.26(0.03)$ & & 0.72 & $2.99(0.005)$ \\
dlnCO $_{2}(-1)$ & -1.30 & $-2.73(0.01)$ & & - & - \\
dlnGDP & 1.27 & $2.59(0.01)$ & & 0.26 & $-2.73(0.01)$ \\
dlnGDP(-1) & -0.92 & $-1.87(0.07)$ & & 1.27 & $1.91(0.06)$ \\
dlnFR & -7.99 & $-3.46(0.002)$ & & 0.22 & $1.11(0.20)$ \\
dlnIMR & 1.47 & $3.48(<0.001)$ & & -0.05 & $-0.23(0.80)$ \\
dDUM & 0.38 & $1.64(0.10)$ & & 0.17 & $1.64(0.10)$ \\
dDUM(-1) & - & - & & -0.27 & $-2.3(0.02)$ \\
dC & -9.5 & $-1.18(0.20)$ & & 1.7 & $0.5(0.60)$ \\
ECM(-1) & -0.85 & $-4.26(0.00)$ & & -0.62 & $-4.89(0.00)$ \\
F-test & $F(8,32): 22.74$ & $(0.00)$ & & $F(7,34): 6.09$ & $(0.00)$ \\
$R^{2}$ & 0.86 & & & 0.66 & \\
DW-statistic & 2.40 & & & 1.92 & \\
\hline
\end{tabular}

ECM, error correction model; ARDL, autoregressive distributed lag; SBC, Schwartz Bayesian criterion; InPuHE, logarithm public health expenditures; InPrHE, logarithm private health expenditures; dlnCO ${ }_{2}$, difference logarithm of carbon dioxide; dlnGDP, difference logarithm of gross domestic product; dInFR, difference logarithm of fertility rate; dInIMR, difference logarithm of infant mortality rate; dDUM, difference dummy variable; $\mathrm{dC}$, difference constant term; DW, Durbin-Watson; (-1), one optimal lag.

rate had no significant impact on long-term health expenditures at the 0.05 significance level. Table 4 shows the results obtained for the short-term effects. A $1.00 \%$ increase in the variable of $\mathrm{CO}_{2}$ emissions resulted in $1.78 \%$ and $0.72 \%$ increases in PuHE and PrHE at a significance level of 0.05 .

The values of the lagged error correction model $(-1)$ were also significant; they were -0.85 and -0.62 for the 2 models, respectively, reflecting annual high-speed adjustments $(-0.85$ and -0.62 ) towards long-run equilibrium. Therefore, the adjustment of the time-series for the long-run equilibrium occurred with a relatively high speed. In general, high values of this coefficient are evidence of a stationary long-term relationship between variables.

The DUM also had a positive effect on PUHE and PrHE in the short and long term. The long-term effect was significant at 0.05; however, it was not significant in the short term. Additionally, the F-value indicating the significance of regression showed an overall high significance of regression $(<0.01)$, and the coefficients of determination $\left(R^{2}\right)$ in the 2 models were equal to 0.86 and 0.66 , respectively, indicating that the models had a relatively high explanatory power. Since the values obtained in the Durbin-Watson test in both models were 2.40 and 1.92 , there was no autocorrelation in the time-series.
In order to evaluate the stability of the model coefficients, the cumulative sum control chart (CUSUM) and CUSUM squared (CUSUMSQ) tests, with a long history in the econometric literature, were used. In the Ho of the CUSUM and CUSUMSQ tests, the stability of the parameters is tested at 0.05 . The confidence interval of the 2 tests is 2 straight lines representing a confidence level of $95 \%$. If obtained value for the CUSUM and CUSUMSQ tests is located between these 2 lines, the Ho indicates the stability of the coefficients. The test values were found to be located within the straight lines, suggesting that the factors were stable at a significance level of 0.05 (Figure 1).

\section{DISCUSSION}

Our results showed a significant positive relationship between environmental pollution and health expenditures in the public and private health sectors. In general, the decline in environmental quality associated with increased air pollution (as indicated by $\mathrm{CO}_{2}$ emissions) is associated with an increased incidence of pollution-induced diseases, enhancing the demand for treatment. Simultaneously, when faced with the problems caused by pollution, the government may choose to pay for the treatment and prevention of air pollution-induced diseases. Other previous studies have found similar results $[3,10,20,22,23]$. In addition, a comparison of the effects of air pollution in the 2 equations suggested that air pollution had a greater impact on PuHE than on PrHE, which may be due to the more important role of the government than the private sector and households in preventing and treating the consequences of air pollution, which is consistent with the results of Fattahi et al. [4]. Thus, air pollution, with its effects on environmental quality, is a phenomenon with a long-term impact on the health sector because it causes chronic diseases, and this finding can be verified by comparing the long-term and shortterm air pollution coefficients in this study and other studies conducted by Yazdi et al. [24] and Pope et al. [25].

Significant and positive impacts of the infant mortality rate and fertility rate on PuHE and PrHE were found, in line with the results of other studies $[26,27]$. However, in both models, the infant mortality and fertility rates had greater impacts on enhancing public than private expenditures, which could be due to greater sensitivity of the public sector and government regarding prevention and reproductive health services over the past several years, whereas the private sector and households have often paid less attention to such services, meaning that 
Plot of cumulative sum of recursive residuals

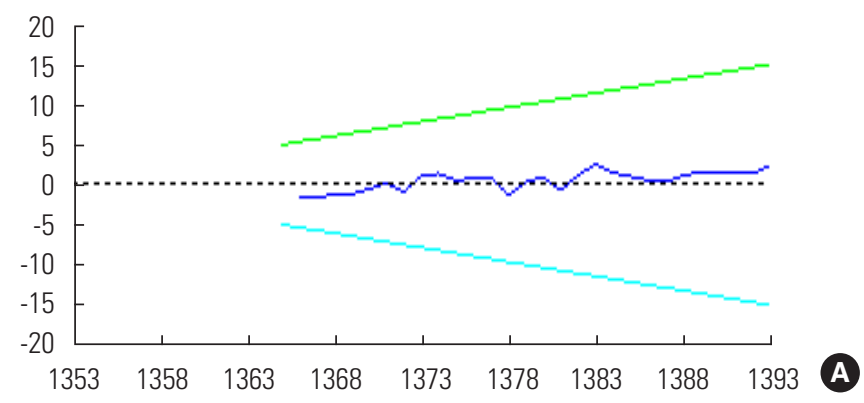

Plot of cumulative sum of squares of recursive residuals

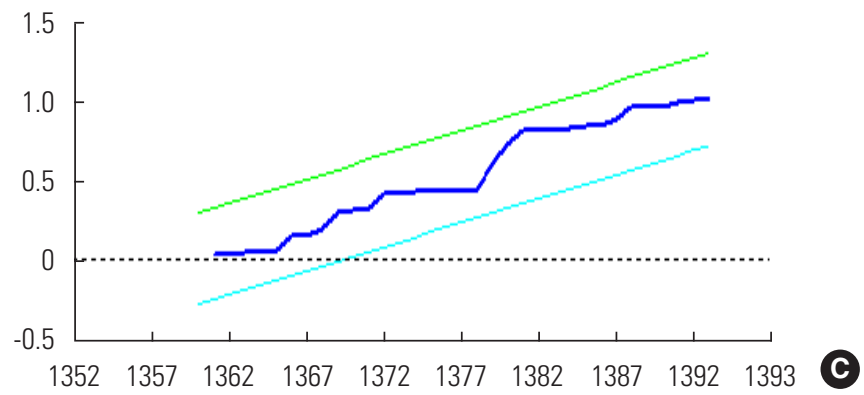

Plot of cumulative sum of squares of recursive residuals

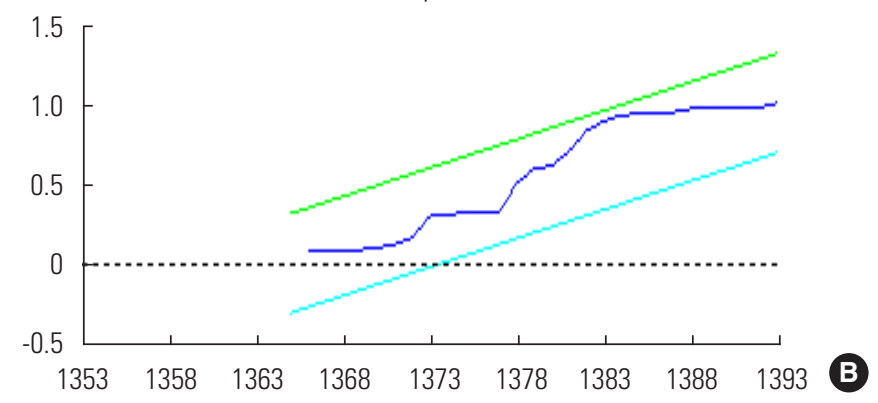

Plot of cumulative sum of recursive residuals

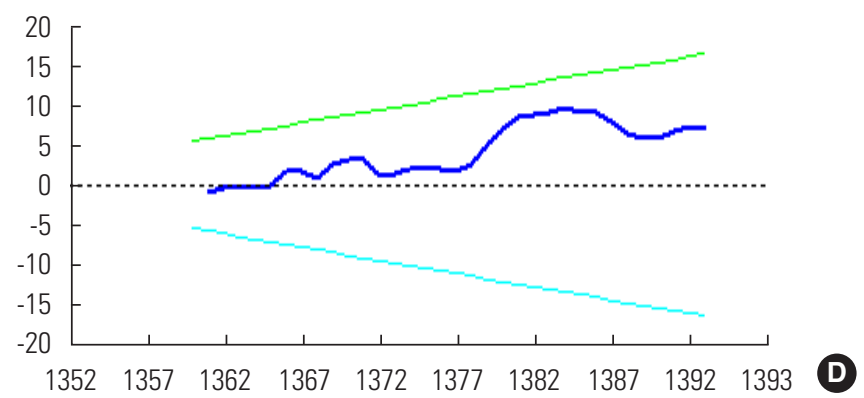

Figure 1. Results of cumulative sum control chart and cumulative sum control chart squared structural stability tests for model 1 (dependent variable: public health expenditures; A, B) and mode 2 (dependent variable: private health expenditures; C, D). The straight lines represent critical bounds at $5 \%$ significance level, respectively.

these measures have been mostly adopted by the government. PuHE were more affected than PrHE by the infant mortality rate, which is consistent with the findings of Fattahi and Barkhordari [28].

Additionally, per capita income in both models had both long-term and short-term significant positive effects on health expenditures, as shown in other studies as well $[8,17,19,20]$. Therefore, due to the greater impact of air pollution than other factors on private and PUHE in this study, it can be concluded that this factor plays a key role in the economic burden of health expenditures, mediated through diseases related to air pollution. Since environmental pollution increases healthcare costs, it results in the loss of financial resources and reduced spending in other sectors for the sake of development. Considering the vital impact of air pollution on health expenditures, especially for the public sector, avoiding its increase (and reducing it, if possible) would naturally decrease the financial burden of governmental expenditures in the health sector in the future. In this regard, appropriate policies to reduce pollution (e.g., preventing the use of worn-out machinery, better monitoring and control of the quality of fuel, and the expansion and development of public transportation) and more at- tention to environmental quality can play an important role in reducing healthcare expenditures in the public and private sectors.

\section{ACKNOWLEDGEMENTS}

This study was funded and supported by the Iran University of Medical Sciences (IUMS); grant no. 95-04-136-29930.

\section{CONFLICT OF INTEREST}

The authors have no conflicts of interest associated with the material presented in this paper.

\section{ORCID}

Pouran Raeissi https://orcid.org/0000-0003-3924-6561

Touraj Harati-Khalilabad https://orcid.org/0000-0002-60031445

Aziz Rezapour https://orcid.org/0000-0003-4032-0802

Seyed Yaser Hashemi https://orcid.org/0000-0003-19489910 
Abdoreza Mousavi https://orcid.org/0000-0001-8786-7309

Saeed Khodabakhshzadeh https://orcid.org/0000-00027062-2038

\section{REFERENCES}

1. Boachie MK, Mensah IO, Sobiesuo P, Immurana M, Iddrisu AA, Kyei-Brobbey I. Determinants of public health expenditure in Ghana: a cointegration analysis. J Behav Econ Finance Entrep Account Transp 2014;2(2):35-40.

2. Gotsadze G, Zoidze A, Rukhadze N. Household catastrophic health expenditure: evidence from Georgia and its policy implications. BMC Health Serv Res 2009;9:69.

3. Fattahi M, Assari A, Sadeghi H, Asgharpour H. Air pollution and public health expenditures: compare developing and developed countries. J Econ Dev Res 2013;11(3):111-132 (Persian).

4. Fattahi M. The role of urbanization rate in the relationship between air pollution and health expenditures: a dynamic panel data approach. Int Lett Soc Humanist Sci 2015;53:68-72.

5. Pearce DW, Turner RK. Economics of natural resources and the environment. Baltimore: John Hopkins University Press; 1991, p. 142-143.

6. Neidell MJ. Air pollution, health, and socio-economic status: the effect of outdoor air quality on childhood asthma. J Health Econ 2004;23(6):1209-1236.

7. Mead RW, Brajer V. Protecting China's children: valuing the health impacts of reduced air pollution in Chinese cities. Environ Dev Econ 2005;10(6):745-768.

8. Jie $\mathrm{H}$. Industrialization, environment and health: the impacts of industrial SO2 emission on public health in China. Chin J Popul Resour Environ 2013;6(1):14-24.

9. World Health Organization. Economic cost of the health impact of air pollution in Europe: clean air, health and wealth; 2015 [cited 2018 May 20]. Available from: http://www.euro. who.int/_data/assets/pdf_file/0004/276772/Economic-costhealth-impact-air-pollution-en.pdf.

10. Mohammadzadeh Y, Ghahramani H, Nazariyan E. Environmental, health and health care costs. Health Inf Manag J 2015; 12(4):495-505 (Persian).

11. Kiani GH, Yari F, Amiri H. An estimation on mortality cost through air pollution in Isfahan city. J Environ Stud 2014;40(1): 247-254 (Persian).

12. Organization for Economic Cooperation and Development. The economic consequences of outdoor air pollution: policy highlights; 2016 [cited 2018 May 20]. Available from: https:// www.oecd.org/environment/indicators-modelling-outlooks/ Policy-Highlights-Economic-consequences-of-outdoor-airpollution-web.pdf.

13. World Health Organization. Global health observatory data repository [cited 2017 Sep 1]. Available from: http://apps. who.int/gho/data/node.main.156?lang=en.

14. Gharagozlou A, alesheykh A, Sajadian M. Analyzed the attitudes of controlling air pollution caused by traffic in urban management in order to provide a framework based on the paradigm of sustainability in financing municipalities: case study metropolis Tehran. Q J Geogr Landsc Zagros 2011;9(3): 157-184 (Persian).

15. Sajadian M. The integration of artificial intelligence, AHP and knowledge discovery in GIS and RS in order to take advantage of experts system in air quality management with emphasis on traffic organization-case study: Tehran municipality [dissertation]. Ahvaz: Ahvaz University; 2011 (Persian).

16. Asadi A. Air pollution and diseases. Sepid Newspaper; 2016 Sep 14 [cited 2017 Jul 10]. Available from: http://sepidonline. ir/d/1395/06/24/\# (Persian).

17. Falahati A, Soheili K, Nazifi M, Abbaspour S. Evaluation and modeling the effect of air pollution on health: using artificial neural network. Iran J Epidemiol 2013;9(2):39-49 (Persian).

18. Barouni M, Harati Khalilabad T, Harati J. The effect of health expenditure (public- private) on human development index in selective countries with high, middle and low income: 2000-2010. J Healthc Manag 2015;6(2):81-91 (Persian).

19. Karatzas G. On the determination of the US aggregate health care expenditure. Appl Econ 2000;32(9):1085-1099.

20. Abdullah $\mathrm{H}$, Habibullah MS. An investigation on trade openness, fiscal policy and economic growth in Malaysia: using an ARDL bounds testing approach. Int J Manag Stud 2009;16(2): 177-197.

21. Pesaran MH, Shin Y, Smith RJ. Bounds testing approaches to the analysis of level relationships. J Appl Econ 2001;16(3):289326.

22. Jerrett M, Eyles J, Dufournaud C, Birch S. Environmental influences on healthcare expenditures: an exploratory analysis from Ontario, Canada. J Epidemiol Community Health 2003; 57(5):334-338.

23. Zheng $X$, Yu Y, Zhang L, Zhang Y. Does pollution drive up public health expenditure? A panel unit root and cointegration analysis; 2010 [cited 2017 Sep 24]. Available from: http://static. sfruc. edu. cn/uploads/soft/100521/2_0822427571. pdf. 
24. Yazdi S, Tamhmasebi Z, Mastorakis N. Public healthcare expenditure and environmental quality in Iran; 2014 [cited 2018 May 20]. Available from: http://www.wseas.us/e-library/conferences/2014/Lisbon/AEBD/AEBD-17.pdf.

25. Pope CA 3rd, Burnett RT, Thurston GD, Thun MJ, Calle EE, Krewski $D$, et al. Cardiovascular mortality and long-term exposure to particulate air pollution: epidemiological evidence of general pathophysiological pathways of disease. Circulation 2004;109(1):71-77.

26. Delpisheh A, Direkvand Moghadam A, Direkvand Moghadam
F. The impact of air pollution on pregnancy outcomes: a systematic review. Iran J Obstet Gynaecol Infertil 2014;17(102):711 (Persian).

27. Dockery DW, Schwartz J, Spengler JD. Air pollution and daily mortality: associations with particulates and acid aerosols. Environ Res 1992;59(2):362-373.

28. Fattahi M, Barkhordari S. The efficiency of public and private health expenditures: DEA approach. J Healthc Manag 2014; 5(3):41-51 (Persian). 